\title{
Costly Stakeholder Participation Creates Inertia in Marine Ecosystems
}

\begin{abstract}
Ecosystems often shift abruptly and dramatically between different regimes in response to human or natural disturbances. When ecosystems tip from one regime to another, the suite of available ecosystem benefits changes, impacting the stakeholders who rely on these benefits. These changes often create some groups who stand to incur large losses if an ecosystem returns to a previous regime. When the participation cost in the decision-making process is extremely high, this can "lock in" ecosystem regimes, making it harder for policy and management to shift ecosystems out of what the majority of society views as the undesirable regime. Public stakeholder meetings often have high costs of participation, thus economic theory predicts they will be dominated by extreme views and often lead to decisions that do not represent the majority viewpoint. Such extreme viewpoints can create strong inertia even when there is broad consensus to manage an ecosystem towards a different regime. In the same manner that reinforcing ecological feedback loops make it harder to exit an ecosystem regime, there are decision-making feedback loops that contribute additional inertia.
\end{abstract}

Keywords: tipping points; hysteresis; regime shifts; stakeholder participation; critical transition; non-linear; threshold; restoration ecology; stakeholder engagement 


\section{Introduction}

Regime shifts ${ }^{1}$ occur in a wide variety of ecosystem types and can be caused by a range of human-induced and natural stressors (Scheffer et al., 2001; Scheffer and Carpenter, 2003; Scheffer, 2009). Systems that tip or cross a threshold often rapidly transition to an alternative state. One of the best-studied and most dramatic state shifts is the sudden loss of transparency in lakes due to eutrophication (Scheffer et al., 1993; Jeppesen et al., 1999). Water clarity often seems to be unaffected by increased nutrient concentrations until a tipping point is passed, after which the lake shifts abruptly from clear to turbid. With this increase in turbidity, submerged plants largely disappear, triggering a decline in animal diversity and resulting in a largely undesirable state. Interestingly, reduction of nutrient concentrations to levels that existed before the regime shift is often insufficient to restore the clear state. Desertification is another example of a regime shift: various lines of evidence indicate that vegetated and desert situations may represent alternative stable states (van de Koppel, 1997; Rietkerk, 1997). When vegetation is lost, runoff increases, and water entering the soil quickly disappears to deeper layers where it cannot be accessed by most plants. Wind and runoff also erode fertile topsoil. As a result, the desert state can be too harsh to be recolonized by plants, even though vegetation would persist once it is present. Woodlands also often demonstrate regime shifts between tree cover and grassy open landscapes. Woodlands, once established, are stable because adult trees cannot be destroyed by herbivores and shading reduces grass cover so that fires cannot spread. Grassy open landscapes can be preserved by herbivores (often in combination with fires) because seedlings of trees are

\footnotetext{
${ }^{1}$ See the "Glossary of Key Terms" box for precise definitions of regime shift, ecosystem state, hysteresis, stakeholder, and other terms used frequently in this paper.
} 
easily eaten. Well-known examples of this type of regime shift are African woodlands in Botswana (Western and Pearl, 1989; Dublin et al., 1990).

Across the globe, marine ecosystems are also experiencing regime shifts, where ecosystems cross a threshold from one alternative state to another (Blenckner \& Niiranen 2013, Kappel et al. in review). Examples include overharvest that leads to population or stock collapses, eutrophication events that lead to dead zones, cumulative disturbances that cause coral reefs to become overgrown with macroalgae, and climatic regime shifts (Brown and Trebilco, 2014; Hare and Mantua, 2000). Ecosystems that have crossed thresholds into new states can revert back to their initial state, but recovery of a system after it crosses a threshold may be delayed or prevented by the presence of reinforcing ecological feedback loops that are present in the alternative regime (Conley et al., 2009; Osman et al., 2010; Nyström et al., 2012). Ecosystem regime shifts affect the benefits humans derive from nature (ecosystem services), such as the economic benefits of resource extraction, tourism, waste absorption and storm protection, and the socio-cultural benefits of recreation, spiritual engagement and biodiversity protection. The longer the alternative regime persists, the more likely humans and institutions adapt and reconfigure to maximize benefits from this new regime.

Shifts in ecosystems can trigger policy conflict because the range of goods and services that stakeholders benefit from in one state are often absent in the other, pitting stakeholder groups with different vested interests against each other. Managers then face decisions about appropriate management interventions in response to ecosystem shifts, and seek intervention strategies that represent compromises and trade-offs among stakeholder groups. Dramatic 
differences in ecosystem states can lead to polarization among stakeholders who favor one ecosystem service over another. For example, a diverse marine ecosystem provides a variety of small benefits to a range of human stakeholders whereas a monoculture system provides large benefits to a small number of stakeholders (e.g., a kelp forest which supports a diverse fish community compared to an urchin barren). Thus, tipping points in ocean ecosystems can often cause polarization among stakeholders. Consequently, management interventions meant to restore lost ecosystem functions and/or biodiversity face difficult negotiations and compromises among stakeholder preferences for different ecosystem states and the benefits they provide.

When regime shifts underwater lead to increased polarization on land, the types of decision-making institutions used to make management decisions may lead to further "lock-in" of the new altered state. Even if there is consensus among the majority of stakeholders to return to a previous state, certain decision-making processes may generate considerable inertia to returning. Thus, much in the same manner that the tipping points literature has discussed positive ecological feedback loops that make it harder to exit an altered state, there may be decisionmaking feedbacks that generate an additional layer of hysteresis in marine ecosystems. 


\section{Participation Costs and Inertia}

Many ocean resource policymaking institutions, as currently designed and implemented, tend to resist ecosystem change and may favor minority, extreme views rather than achieve outcomes desired by most of society. These institutions can unintentionally reinforce the altered regime, even if the management objective is to restore the previous regime. Ocean and resource management in the U.S. typically requires a process of public stakeholder meetings that influences and drives agency decisions (Bingham et al., 2005). For example, the Magnuson Fishery Conservation and Management Act specifies the way in which interested parties' views will be heard by requiring "public hearings ... to allow all interested persons an opportunity to be heard in the development of fishery management plans." ${ }^{2}$ However, participation in the decision process is often very costly to individuals, for example in time spent preparing submitted comments, distance traveled to attend hearings, or earnings sacrificed (see Table 1). The political economy literature on participatory governance suggests that if the cost of participating in these meetings is very high then this will serve to lock in the preferences of a few, and not necessarily the preferences of the many. Osborne et al. (2000) study a collective decision-making process in which people interested in an issue may participate in a meeting at a cost, and the resulting decision is a compromise among the participants' preferences. In deciding whether to participate, each person compares the cost of participation with the impact of her presence on the compromise. Much US ocean policy is made through such a process. State and federal regulators are required to seek out and respond to public comment on proposed regulations; participation in the regulatory process is costly because participants spend time preparing submissions and may

\footnotetext{
${ }^{2}$ Title 16 U.S. Code $\$ 1852(\mathrm{~h})(3)$.
} 
have to travel considerable distances to hearings. As an extreme example, decisions relating to fisheries management in Hawai'i are often made at Western Pacific Regional Fishery Management Council meetings held thousands of miles away in American Sāmoa or Guam.

The theoretical model of Osborne et al. (2000) can be summarized as follows. A group of $n$ stakeholders must collectively choose a policy, which is represented as a real number lying somewhere between 0 and infinity. Denote stakeholder $i$ 's favorite policy by $x_{i}$. Each stakeholder cares about the remoteness of the collectively chosen policy from her favorite policy. Specifically, stakeholder $i$ 's valuation of the policy $x$ is $v\left(x_{i}-x\right)$, and this value function is maximized when $x_{i}=x$. Each stakeholder chooses whether or not to attend a meeting, at which a policy is selected. Every person who attends a meeting bears the cost $c>0$. A person who chooses to attend is defined as a "participant". The outcome of the meeting is the median favorite policy of all the participants.

The question is now, who will attend the meeting and what will the outcome be? Osborne et al. (2000) assume that a stakeholder decides to participate on the basis of how much her participation affects the outcome, taking as given the participation decisions of other stakeholders. If and only if the value of the change in outcome associated with participation is greater than the participation cost does the stakeholder participate. All else equal, stakeholders with lower participation costs will be more likely to participate, stakeholders whose participation causes a larger shift in the outcome will be more likely to participate, and stakeholders who value a marginal change in the outcome more highly will be more likely to attend. In equilibrium, stakeholders whose favorite policy is near the anticipated outcome are less likely to participate 
than those whose favorite policy is far from the anticipated outcome. That is, stakeholders with moderate preferences do not participate in costly stakeholder meetings. Intuitively, participation by stakeholders close to the outcome does not move the outcome enough to justify their participation costs. So, in equilibrium, only stakeholders whose favorite positions are sufficiently far from the compromise position participate.

Thus, the theoretical model of Osborne et al. (2000) predicts that if participation costs are high, stakeholder meetings will de dominated by extreme viewpoints. Meetings dominated by extreme viewpoints will reach policy decisions that do not represent the majority viewpoint and are often extreme. The intuition for this theoretical result is as follows. Suppose there is a random chance that each stakeholder will be prevented from attending, even if they intend to. Assume the probability is the same for all stakeholders and is independent. It can be shown that there will be an interval of moderates who do not participate and two groups of extremists of equal or almost equal sizes who intend to participate. As a result, the outcome of the meeting will be an extreme decision unless equal numbers of intended participants on each side are prevented from attending. Furthermore, the extreme outcome will fluctuate from one extreme to the other based on who is randomly prevented from attending.

\section{[Table 1 approximately here]}

To summarize, the theoretical model in Osborne et al. (2000) generates three key results. First, individuals with a moderate position do not participate in the decision-making process. Second, only a small proportion of all affected individuals choose to participate. Third, if the 
compromise is the median position, then the outcome tends to vary randomly and is likely to be an extreme position. Thus, if the cost of participating in meetings is high, ocean policy meetings will tend to be dominated by extreme viewpoints (i.e., those who face large gains or costs from proposed changes). Our basic argument is the following. Regime shifts not only alter ecosystems, they alter the constituents who benefit from the ecosystem. If a regime shift creates a new group of constituents that stands to make large losses or gains if the system returns to its previous state, then the theory of Osborne et al. (2000) predicts that this will further lock an ecosystem into the altered state. Decision-making processes that are very costly will be dominated by extremists (making it harder to find compromises) and lead to extreme policy decisions. Thus, hysteresis can become stronger as the result of decision-making institutions and processes used to make management decisions.

Examples of this shift in stakeholder standing include efforts to introduce marine mammals in areas where they were previously abundant. Harvesting of marine mammals removed predatory pressure on their prey. A concomitant rise in prey abundance led to the emergence of an industry heavily dependent on harvesting the abundant prey (e.g., urchin after otter removal, cod/salmon after seal removal). A key step in restoring this altered system towards its "original" state would be the introduction of previously extirpated marine mammals. However, there is now a group with a lot to lose if marine mammals are reintroduced. Even though the majority of public opinion might be in support of reintroduction, decisions made through meetings with costly participation will tend to support extreme positions and lead to considerable inertia against moving towards a socially desirable outcome. The next section outlines two case studies that fit this general description. 
The tendency for high participation costs to lead to over-representation of groups with more resources (often holding extreme viewpoints) echoes observations in the broader political sphere. Specifically, costly participation does "a good job of representing intense interests but a poor job of guaranteeing political equality" (Berinsky, 2004). Furthermore, political engagement draws "disproportionately from those groups more advantaged in the resources that aid participation, such as education and disposable income. Activists therefore differ in politically consequential ways from those who do not engage in politics" (Berinsky 2004). Consequently, the ultimate outcome of encouraging participatory processes in management and policy, as has been the general trend in recent decades, can be the widespread perception that government serves private interests over the will of the people. Sixty-four percent of Americans in 1964 believed government was run for the benefit of the public. But in 2008, only 29 percent of Americans believed that policymakers were working in their interest; instead, 69 percent of Americans in 2008 thought lawmakers passed legislation that benefited only a few big interests (Grossman 2014). As further evidence, a national survey of US citizens in 2014 found that voters with the most extreme ideologies are also the most likely to vote and make campaign contributions. Non-voters tend to be those with centrist viewpoints and rarely contribute to political campaigns. Polarization is thus greatest among those who are the most engaged and active in the political process (Pew Research Center, 2014). This tendency is particularly true for regulatory decisions that affect corporations. Because business interests tend to resist new laws (Grossman, 2014), especially when businesses have been designed around the status quo, participatory political processes can increase inertia to change when only business interests are willing or able to pay the cost of participation. 


\title{
3. Case Studies of Regime and Stakeholder Shifts
}

\author{
3.1 Otter-Kelp Dynamics in the North Pacific Ocean
}

The presence or absence of sea otters at ecologically effective (Soule et al., 2003) population densities can trigger two alternative states for rocky reef ecosystems along the coastlines of the Northeast Pacific Ocean (Figure 1A). Where otters are present, benthic invertebrates (including herbivorous sea urchins) are rare, and the seafloor tends to be covered with kelps and other fleshy macroalgae (this state is known as a kelp-dominated ecosystem). Where otters are absent, there is a proliferation of their benthic invertebrate prey, grazing intensity increases, and the distribution and abundance of kelps become greatly diminished (this ecosystem state is known as an urchin barren). As sea otters are either repatriated to places from which they have been long absent or removed from places at which they have been long present, the ecosystem state transitions between kelp forests and urchin barrens occur as abrupt shifts (Estes et al., 2010). Transitions between urchin and kelp dominated states are often characterized by hysteresis (Ling et al. 2015).

[Figure 1 approximately here]

\footnotetext{
Abundant sea otters and kelp-dominated systems prevailed across the North Pacific rim for at least several million years, from the late Miocene/Pliocene to the beginning of the Pacific maritime fur trade in 1742. Otter populations were hunted to the brink of extinction over the next
} 
150 years. In the absence of sea otters, sea urchins and other benthic macroinvertebrates (e.g., abalones, clams, crabs) proliferated and kelp forests dwindled. This shellfish-rich and kelpimpoverished ecosystem state is what European colonizers encountered as they settled and lived along the west coast of North America over the last several hundred years. Commercial and recreational shellfisheries developed during this period, made possible by the ecosystem's otterfree state. Shellfisheries became an important part of peoples' livelihoods and cultures, especially in coastal communities from southeast Alaska to central Baja California. This state of affairs continued through the 1960s, at which time the growing otter population in central California expanded beyond the remote Big Sur region and sea otters were reestablished in southeast Alaska, British Columbia and Washington by way of relocations from elsewhere in Alaska. The recovering sea otter populations in turn drove shellfish populations that had expanded in their absence back down to low abundances. Some people whose livelihoods and culturally important activities depended on shellfish and shellfisheries largely opposed sea otter recovery in California (Booth, 1988). ${ }^{3}$ The degree to which future sea otter management actions conform to the wishes of these stakeholders will add to the strength of hysteresis in the sea otterkelp forest system.

Sea otters are protected by national, provincial, and state laws throughout most of their current range in Russia, the U.S. and Canada. Any management actions that would limit the sea otter's range to protect shellfisheries is therefore illegal. Indigenous Alaskans are permitted to take sea otters and other marine mammals for traditional uses although they are not permitted to

\footnotetext{
${ }^{3}$ For alternative viewpoints on sea otter recovery from Indigenous peoples whose livelihoods and cultural activities also rely on shellfish see Salomon et al. (2015), who describe the diversity of viewpoints regarding otter recovery in British Columbia, Canada.
} 
do this in a wasteful manner. The law specifies that any market products from marine mammals must be "significantly altered", which means that unworked pelts cannot be sold. These provisions of the Marine Mammal Protection Act prevent the harvest of sea otters by indigenous Alaskans for de facto shellfisheries management. However, because of strident complaints by indigenous groups and local non-indigenous shellfish fisheries interests in southeast Alaska to state and federal politicians, the U.S. Fish and Wildlife Service (the federal authority for sea otter management) is under extreme pressure to interpret the law in a way that will provide relief to shellfisheries from competition with sea otters. The conflict between sea otters and shellfisheries in southeast Alaska remains at present unresolved (Larson et al., 2013).

\subsection{Gulf of Maine Lobster Fishery}

The Gulf of Maine (GOM) and surrounding regions have been exploited for centuries. Historically, Atlantic cod was the most economically valuable species in the northwest Atlantic and the cod fishery played an important role in the culture, livelihoods, and human economies of coastal communities. The cod fishery was invaluable to international fishing fleets and communities as well. Prior to the 1950s (the 'initial state'), the ecosystem structure and function was relatively resilient to exploitation. Groundfish predators (e.g., cod, haddock, hake) were the dominant species in the region and their abundances were at high enough levels to regulate prey populations (e.g., lobsters, sea urchins).

Starting in the 1960s, technological advances in transportation and fishing gear, the expansion of international fishing fleets in U.S. waters, and the resurgence of local interest in 
groundfish fisheries after the establishment of an exclusive economic zone contributed to an unprecedented level of fishing pressure on the GOM ecosystem (Steneck et al., 2011). In response, cod and other groundfish populations in coastal and offshore waters began to decline. The coastal cod populations started showing signs of collapse by the 1970s followed by the offshore populations in the early 1990s. In the mid-1990s, severe catch limits and a fishing moratorium on some stocks were established in the Gulf of Maine and surrounding U.S. and Canadian waters. Strict fishing regulations were also established for other groundfishes, including haddock and yellowtail flounder (Fogarty and Murawski, 1998)

Despite restricted fishing efforts, Atlantic cod still do not show signs of recovery since their collapse. The slow recovery has been attributed to changes in climate, ocean conditions and food availability and to a major shift in food web dynamics (Pershing et al., 2013). With the loss of a major predator in the system, the GOM lobster population has surged since the early 1990s. Sea urchins and other groundfish prey also increased, although the sea urchins were quickly depleted under heavy exploitation. In contrast, the lobster fishery boomed and continues to dominate the total economic value of marine fisheries in this system (Figure 1B). The GOM lobster population is essentially a lucrative monoculture (Steneck et al., 2011).

There is a difference of opinion on the "socially desirable state" of the GOM ecosystem. On one hand, some scientists and stakeholders contend that a return to an ecologically diverse ecosystem is critical to strengthen the resilience of the social and economic system in the region. On the other hand, government agencies and fishery managers are interested in taking action to reduce the economic vulnerability of the lobster fishery and larger community, but are not 
making real efforts to improve the biodiversity of the ecosystem (Steneck et al. 2011). In addition, the coastal communities and economies have adapted to the new ecosystem state, making it difficult to implement change. The Maine region is now synonymous with lobster, not cod. This inertia may only get stronger as younger generations, who have little memory of the rich biodiversity in the GOM decades ago, become the leading stakeholders in the region.

\section{Evidence that Participation Costs Exacerbate Inertia in Ocean Policy}

Do the decision-making institutions used to create and change US ocean policy actually generate inertia as hypothesized? By requiring stakeholder participation but using a process with high participation costs (across the many dimensions of cost; Table 1), resource management has the potential to favor extreme views that often do not represent the majority and tend to preserve the status quo. This section summarizes some empirical and anecdotal evidence in support of this claim. An oft-cited example of stakeholder meetings with high participation costs are US fishery council meetings. The Magnuson Fishery Conservation and Management Act requires public hearings to be held that allow all interested persons an opportunity to be heard in the development of fishery management plans. Turner and Weninger (2005) obtained logbook data on harvest in the Mid-Atlantic surf clam and ocean quahog fishery. They then combined this data with public records of individual tradable quota ownership and the minutes of regulatory meetings where total allowable catches are discussed to create a unique dataset on the universe of firms affected by regulatory outcomes and their participation in stakeholder meetings. They also collected information about what was said at each meeting. Using this data, they are able to show that firms with a preference for extreme, rather than moderate, policies are much more likely to participate in these public stakeholder meetings where regulation is determined. They 
also find that participation rates are higher for larger, more valuable, firms and for firms located geographically close to the meeting location. These results clearly support the theoretical argument that polarization and partisanship should emerge under the current system used to manage fisheries in U.S. federal waters.

\begin{abstract}
Allen (1991) describes a conflict between conservation-minded sport fishers and extraction-minded commercial fishers in Rhode Island. Both groups took fairly extreme positions and the attendance at two successive public hearings was lopsided in different directions, producing a policy that was first pro-conservation and then pro-extraction. Turner and Weninger (2005) cite the public hearings held by the New England Fishery Management Council (1985, p. 9.45) as another example: two different groups of fishers (gillnetters and trawlers) with extremely divergent viewpoints on appropriate policy actions attended successive public hearings in lopsided proportions. The result was a policy that first favored one group and then the other.
\end{abstract}

In a theoretical model, Smith et al. (2010) examine political economy factors surrounding the creation of marine reserves. They demonstrate that the implementation of marine reserves can lead to large divergences in the level of opposition to a reserve. Critically, they examine which factors affect the standard deviation of opposition to reserves and not just the mean or median level of opposition. Marine reserves with weak support but a low variance (little divergence in viewpoints) are actually more likely to be implemented than reserves with strong support but extremely divergent viewpoints (see Figure 2). As an empirical example, opposition to marine reserves by recreational fishermen was a key hurdle to the creation of the Great Barrier 
Reef Marine Park, which relied on public stakeholder meetings during the design process. Sutton (2006) sought to understand the variables that predict participation by recreational fishers in public stakeholder meetings, and investigated differences between participants and nonparticipants. In a survey of recreational fishers in Queensland, Australia, only 28\% of respondents reported participating in public meetings regarding issues affecting recreational fisheries. Participation in public meetings was positively related to the extremity of a recreational fisher's viewpoint. There was no effect of gender, income, or years of fishing experience on participation. Participants and non-participants differed significantly in their beliefs about fisheries management and the threats facing recreational fisheries. They also differed in terms of their approval of fishing regulations. This leads Sutton (2006) to conclude that recreational fishers who participate in public stakeholder meetings may not be representative of the wider recreational fisher population, in line with our hypothesis.

[Figure 2 approximately here]

Bard (2003) presents the results of polls conducted by Seaweb on public perceptions of MPA establishment, two national and one California-specific. Both national polls showed strong support for MPA establishment and increased ocean protection. In a poll conducted in February 2001, there was overwhelming support (83\%) to establish a system of marine protected areas in U.S. waters. Within California, there was strong support (71\%) for establishing fully protected areas in the ocean in which all extractive activities are prohibited, including oil drilling, mining, and all commercial and recreational fishing. Interestingly, recreational fishers supported the establishment of fully protected areas. Of those recreational fishers polled, 68\% supported fully 
protected areas. This is in stark contrast to the opposition to marine reserves voiced by the recreational fishing community (especially the United Anglers of Southern California) during the stakeholder participation process under the MLPA. In reflecting on the MLPA process, the Facilitator's report for the Central California Coast concluded that stakeholder meetings could have been improved if more weight had been given to moderate stakeholders: "Another choice would have been to recruit members of local communities who were not closely aligned with a specific fishing or conservation interest. Additionally, the I-Team [Initiative Team] could have asked for a more overt commitment to take the needs of other stakeholders and the greater region into account" (McCreary and Poncelet, 2006, p. 8.; Gleason et al., 2010; Fox et al., 2013).

Similar findings to Bard (2003) are reported by Eddy (2014). In order to understand social factors influencing marine reserve creation in New Zealand, public surveys were conducted in 2005 and 2011 about marine protection. These results were then compared to actual marine protection levels. On average, the New Zealand public thought that $30 \%$ of New Zealand's marine environment was protected by no-take marine reserves, and that $36 \%$ should be protected, while in fact only $0.3 \%$ is protected by no-take marine reserves. This demonstrates a clear disconnect between the desired state of the majority of stakeholders and the actual management and regulation of the ecosystem. Eddy (2014, p.61) specifically lists "polarised views and opposition from some stakeholders" as one of the barriers to marine reserve implementation. As an empirical example, he presents the case of the Taputeranga marine reserve where fishers who stood to lose access to fishing grounds were the biggest opponents and worked to stall the process and prevent the reserve from being established (Gardner and Bell, 2008). 
Finally, Suman et al. (1999) looked at the opinions of commercial fishers, dive operators, and members of local environmental groups regarding the zoning process in the Florida Keys. Surveys requested responses regarding the degree of public participation, their perceptions and acceptance of the zoning strategy and the process of its design, and the expected outcomes of the zoning strategy. Many responses show significant differences among the three groups. Fishers (who would experience small initial losses) felt highly alienated from the process relative to dive operators and environmental groups $(p<0.05)$. Dive operators (who had the most to gain) demonstrated the highest levels of participation in the designation process $(p<0.05$, outcome is attendance at NOAA meetings and comparison groups were environmental groups and commercial fishers).

\section{Prescriptions for reforming decision-making processes to reduce inertia}

Section 2 outlined a theoretical model that predicts that high participation costs will cause stakeholder meetings to reach outcomes that favor extremist stakeholders. If ecosystem regime shifts provide large benefits to a few stakeholders at the expense of many then high participation costs may further lock-in the regime shift. Sections 3 and 4 summarized a number of empirical examples that support this conclusion. Thus, key and often overlooked factors in maintaining ecosystem regime shifts are a high cost of stakeholder participation in decision-making processes and inequitable distribution of financial, organizational, and social capacity across stakeholders to participate in decision processes (Table 1). These factors can exist in many management scenarios but their repercussions are especially pronounced when ecosystems upon which 
humans depend display sharp tipping points between alternative regimes. The obvious next question is how policymakers can potentially address the fact that high participation costs create an additional layer of inertia in marine ecosystems prone to tipping points. A number of options exist to improve stakeholder participation and reduce inertia and disparity, with most focused on realigning the cost or responsibility of participation with government institutions rather than stakeholders. A summary of these options is presented below. These prescriptions should not be interpreted as carte blanche endorsements since every ecosystem and management regime has its own unique requirements, opportunities, and constraints.

(i) Decentralize decision-making. Decisions need to be informed not only by the spatial scale of the resource but also the scale of affected communities. For example, in fisheries management this might involve dividing regional fisheries councils into smaller geographic groups. In other contexts, holding meetings in more communities would allow greater participation. Extension agents from management organizations could interact directly with small focus groups of resource users at convenient locations and times. Decentralization of decision-making would allow for more local community-based participation and management.

(ii) Embrace new technologies. Decision-making processes should use recent advances in technology that allow low-cost online participation. Halpern (2014) discusses ideas for improving and enriching electronic public participation in agency rulemaking so that agency rules incorporate different kinds of expertise and are resistant to inappropriate political interference. An important caveat is that lowering the costs of participation through technology may lower the weight that decision-makers place on technology-assisted participation. Hence the 
view that attending a meeting carries more weight than writing a letter, which is more influential than sending an email or signing an online petition ("clicktivism"). Thus, participation through new technologies should probably require some minimal effort so that technology-assisted participation is viewed as equally important.

(iii) Engage and/or represent all relevant stakeholders. Agency rulemaking should be changed to legally require incorporation of a diverse and broader spectrum of expertise. Agencies should try to identify all relevant stakeholders and ensure that decision-making participation reflects the true underlying diversity of opinion and its relative representation. Sutton and Tobin (2012) suggest using the social resilience construct for identifying fishers who are likely to be vulnerable to changes. They argue that identifying and managing for social resilience in the Great Barrier Reef would aid in the design and implementation of policies that minimize the impacts on resource users and lead to more inclusive and sustainable management. In a similar vein to Sutton and Tobin (2012), Suman et al. (1999) suggest that managers could conduct surveys up front to better identify public stakeholders and work to ensure their participation. One creative idea proposed by Turner and Weninger (2005) is to make fisheries management akin to jury duty: require a small subset of randomly selected stakeholders to attend meetings in order to increase the likelihood of moderate voices in the debate.

(iv) Improve planning documents. Too often materials presented at and used in decision processes are not user-friendly or are tailored to the interests of specific user groups (Suman et al., 1999). Agencies should work with communication experts experienced in how to convey 
information to different constituencies. Documents should also be understandable by major user groups that do not speak English.

(v) Encourage dialogue. Many stakeholder meetings could evolve from rigid forms of one-way communication to flexible forums with open discussion. For example, public meetings could be structured as facilitated discussion groups rather than spoken (prepared) statements by individuals to an advisory panel. Such dialogue facilitates a deeper understanding of stakeholder views and encourages greater participation. Extension agents from management organizations should interact directly with small focus groups of resource users at convenient locations and times. As an example, starting in February 2014, the South Atlantic Fishery Management Council has introduced informal "port meetings" where council members and staff go out into fishing communities to meet and talk informally with all sectors of the snapper grouper fishery about their ideas on management.

How do these prescriptions connect to our main hypothesis that high participation costs can create inertia in marine ecosystems? Assuming that returning an ecosystem to a previous regime is socially desirable but costly for some stakeholder groups, then all of these prescriptions should make it easier to enact decisions that push the ecosystem back to the previous regime. For example, decentralizing decision-making lowers the cost of participating in stakeholder processes thus, based on the theoretical model of Osborne et al. (2000), this should lead to the stakeholder process choosing policies that are closer to the true median viewpoint of all relevant stakeholders. As another example, making participation in resource management similar to jury duty (a random sample of relevant stakeholders is selected and legally required to participate) 
would, in theory, assure that the stakeholders who do participate in the process are an unbiased and representative sample of the true population. Thus, their decisions should reflect the median or majority view of the true population of relevant stakeholders.

\section{Conclusion}

Decision-making processes with a high cost of participation may add another layer of complexity to the science of ocean tipping points. The higher the cost of participation, the more likely that stakeholder meetings will be dominated by extreme viewpoints and remain deadlocked. If decisions are reached, they are likely to be extreme. This creates inertia that makes it even harder to enact management actions necessary to return to a previous state. Thus, decision-making institutions can strengthen hysteresis and stabilize alternative states.

This theoretical argument appears to be borne out in a number of empirical examples. Local extinctions of sea otters from the coastal oceans of western North America in the Pacific maritime fur trade led to a regime shift from kelp forests to urchin barrens, enabling shellfish fisheries for commercial, subsistence, and cultural purposes. Consequently, there is contentious debate about whether managers should allow natural, on-going otter reestablishment to proceed unhindered. Similarly, the Gulf of Maine food web was once dominated by Atlantic cod, which in turn supported ecological and human communities based on cod and other groundfish. Overfishing of cod in the first half of the 20th century led to its eventual collapse and replacement by lobster as the dominant consumer, enabling a lucrative lobster fishery 
meetings. A number of potential changes that could lower this cost have been proposed. Some of these changes are quite significant such as decentralizing decision-making, embracing new technologies, and engaging all stakeholders. Others would be much easier to implement such as improving planning documents and modifying the format of dialogue when seeking stakeholder input.

Most of the ideas presented above represent a large directional shift from the traditional model of stakeholder participation where individuals travel to a hotel conference room and speak their views through a microphone. Most will require additional time and resources from policymakers and agencies, but as ecosystems continue to undergo regime shifts, it is financially prudent to identify the ecological and social feedback loops that may inhibit ecosystem recovery. Management needs to remove rather than exacerbate obstacles to the implementation of sensible, broadly supported actions (Stringer et al., 2006). 


\section{References}

Allen, G. (1991) Rhode Island Flounder (Part 1). The Fisherman, 12-13.

Bard, D. (2003) Americans' Attitudes Toward Marine Protected Areas and Fully Protected Marine Reserves. Proceedings of the 13th Biennial Coastal Zone Conference, Baltimore, MD July 13-17, 2003

Berinsky, A. J. (2004). Silent voices: Public opinion and political participation in America. Princeton University Press.

Bingham, L. B., Nabatchi, T., \& O'Leary, R. (2005). The new governance: Practices and processes for stakeholder and citizen participation in the work of government. Public administration review, 65(5), 547-558.

Blenckner, T. Niiranen, S. (2013). Biodiversity - Marine Food-Web Structure, Stability, and Regime Shifts. In: Climate Vulnerability, R.A. Pielke, Vol 4: Ecosystem Function and Services. Pages 203-212. Elsevier. ISBN: 978-0-12-384704-1

Booth, W. (1988). Reintroducing a political animal. Science, 241(4862), 156.

Bouamrame, M. (2006). Biodiversity and stakeholders: concertation itineraries. Biosphere reserves, technical notes 1. MAB Secretariat, Parigi.

Briske, D. D., Fuhlendorf, S. D., \& Smeins, F. E. (2006). A unified framework for assessment and application of ecological thresholds. Rangeland Ecology \& Management, 59(3), 225-236.

Brown, C. J., \& Trebilco, R. (2014). Unintended cultivation, shifting baselines, and conflict between objectives for fisheries and conservation. Conservation biology, 28(3), 677-688.

Carpenter, S. R., \& Folke, C. (2006). Ecology for transformation. Trends in Ecology \& Evolution, 21(6), 309-315.

Casini, M., Hjelm, J., Molinero, J. C., Lövgren, J., Cardinale, M., Bartolino, V., \& Kornilovs, G. (2009). Trophic cascades promote threshold-like shifts in pelagic marine ecosystems. Proceedings of the National Academy of Sciences, 106(1), 197-202.

Conley, D. J., Paerl, H. W., Howarth, R. W., Boesch, D. F., Seitzinger, S. P., Havens, K. E., ... \& Likens, G. E. (2009). Controlling eutrophication: nitrogen and phosphorus. Science, 323(5917), 1014-1015.

Dublin, H. T., Sinclair, A. R., \& McGlade, J. (1990). Elephants and fire as causes of multiple stable states in the Serengeti-Mara woodlands. The Journal of Animal Ecology, 1147-1164.

Eddy, T. D. (2014). One hundred-fold difference between perceived and actual levels of marine protection in New Zealand. Marine Policy, 46, 61-67. 
Estes, J. A., Peterson, C. H., \& Steneck, R. S. (2010). Some effects of apex predators in higherlatitude coastal oceans. Trophic cascades: predators, prey and the changing dynamics of nature. Island Press, Washington, DC, USA, 37-54.

Estes, J. A., Tinker, M., \& Bodkin, J. L. (2010). Using ecological function to develop recovery criteria for depleted species: sea otters and kelp forests in the Aleutian archipelago. Conservation Biology, 24(3), 852-860.

Fogarty, M. J., \& Murawski, S. A. (1998). Large-scale disturbance and the structure of marine systems: fishery impacts on Georges Bank. Ecological Applications, 8(sp1), S6-S22.

Fox, E., Poncelet, E., Connor, D., Vasques, J., Ugoretz, J., McCreary, S., ... \& Gleason, M. (2013). Adapting stakeholder processes to region-specific challenges in marine protected area network planning. Ocean \& Coastal Management, 74, 24-33.

Gardner, J. P. A., \& Bell J. J. (2008) The Taputeranga marine reserve. 1st ed.. Wellington, New Zealand: Publishers.

Gleason, M., McCreary, S., Miller-Henson, M., Ugoretz, J., Fox, E., Merrifield, M., ... \& Hoffman, K. (2010). Science-based and stakeholder-driven marine protected area network planning: A successful case study from north central California. Ocean \& Coastal Management, 53(2), 52-68.

Greene, C. H., \& Pershing, A. J. (2007). Climate drives sea change. Science, 315(5815), 1084.

Grossmann, M. (2014). Artists of the Possible: Governing Networks and American Policy Since 1945. Oxford University Press.

Halpern, M. (2014). Comments on Rulemaking vs. Democracy: Judging and Nudging Public Participation That Counts. Environmental Law Reporter

Hare, S. R., \& Mantua, N. J. (2000). Empirical evidence for North Pacific regime shifts in 1977 and 1989. Progress in oceanography, 47(2), 103-145.

Jeppesen, E., Søndergaard, M., Kronvang, B., Jensen, J. P., Svendsen, L. M., \& Lauridsen, T. L. (1999). Lake and catchment management in Denmark. In The Ecological Bases for Lake and Reservoir Management (pp. 419-432). Springer Netherlands.

Kappel, C.V., C. Scarborough, B.S. Halpern, M.E. Hunsicker, K.A. Selkoe. in review. Marine ecosystem shifts around the world.

Larson, S. D., Hoyt, Z. N., Eckert, G. L., \& Gill, V. A. (2013). Impacts of sea otter (Enhydra lutris) predation on commercially important sea cucumbers (Parastichopus californicus) in southeast Alaska. Canadian Journal of Fisheries and Aquatic Sciences, 70(10), 1498-1507. 
Ling, S. D., Scheibling, R. E., Rassweiler, A., Johnson, C. R., Shears, N., Connell, S. D., ... \& Clemente, S. (2015). Global regime shift dynamics of catastrophic sea urchin overgrazing. Philosophical Transactions of the Royal Society of London B: Biological Sciences, 370(1659), 20130269.

McCreary, S., \& Poncelet, E. (2006) Revised MLPA Central Coast Project Facilitators' Report. Marine Life Protection Act Initiative Central Coast Project.

Montefalcone, M., Parravicini, V., \& Bianchi, C. N. (2011). Quantification of coastal ecosystem resilience. Treatise on estuarine and coastal science, 10, 49-70.

New England Fishery Management Council (1985). Fishery Management and Environmental Impact Statement Regulatory Impact Review and Initial Regulatory Flexibility Analysis for the Northeast Multi-species Fishery (Saugus, MA: National Marine Fisheries Service).

Nyström, M., Norström, A. V., Blenckner, T., de la Torre-Castro, M., Eklöf, J. S., Folke, C., ... \& Troell, M. (2012). Confronting feedbacks of degraded marine ecosystems. Ecosystems, 15(5), 695-710.

Osborne, M. J., Rosenthal, J. S., \& Turner, M. A. (2000). Meetings with costly participation. American Economic Review, 90(4), 927-943.

Osman, R. W., Munguia, P., \& Zajac, R. N. (2010). Ecological thresholds in marine communities: theory, experiments and management. Marine Ecology Progress Series, 413, 185187.

Pershing, A. J., Head, E. H., Greene, C. H., \& Jossi, J. W. (2010). Pattern and scale of variability among Northwest Atlantic Shelf plankton communities. Journal of Plankton Research, fbq058.

Pew Research Center, June, 2014, "Political Polarization in the American Public"

Pomeroy, R. S., \& Rivera-Guieb, R. (2005). Fishery co-management: a practical handbook. CABI.

Rietkerk, M., van den Bosch, F., \& van de Koppel, J. (1997). Site-specific properties and irreversible vegetation changes in semi-arid grazing systems. Oikos, 241-252.

Runge, J. A., Kovach, A. I., Churchill, J. H., Kerr, L. A., Morrison, J. R., Beardsley, R. C., ... \& Townsend, D. W. (2010). Understanding climate impacts on recruitment and spatial dynamics of Atlantic cod in the Gulf of Maine: Integration of observations and modeling. Progress in Oceanography, 87(1), 251-263.

Salomon, A.K., B.J. Wilson, E. White, N. Tanape Sr., T. M. Happynook. (2015). First Nations perspectives on sea otter conservation in British Columbia and Alaska; Insights into coupled human-ocean systems. In: Sea Otter Conservation. Eds: S. Larson, G. VanBlaricom and J. Bodkin. Elsevier. 
Scheffer, M. (2009). Critical transitions in nature and society. Princeton University Press.

Scheffer, M., \& Carpenter, S. R. (2003). Catastrophic regime shifts in ecosystems: linking theory to observation. Trends in ecology \& evolution, 18(12), 648-656.

Scheffer, M., Carpenter, S., Foley, J. A., Folke, C., \& Walker, B. (2001). Catastrophic shifts in ecosystems. Nature, 413(6856), 591-596.

Selkoe, K. A., Blenckner, T., Caldwell, M. R., Crowder, L. B., Erickson, A. L., Essington, T. E., ... \& Kappel, C. V. (2015). Principles for managing marine ecosystems prone to tipping points. Ecosystem Health and Sustainability, 1(5), 1-18.

Smith, M. D., Lynham, J., Sanchirico, J. N., \& Wilson, J. A. (2010). Political economy of marine reserves: Understanding the role of opportunity costs. Proceedings of the National Academy of Sciences, 107(43), 18300-18305.

Soulé, M. E., Estes, J. A., Berger, J., \& Del Rio, C. M. (2003). Ecological effectiveness: conservation goals for interactive species. Conservation Biology, 17(5), 1238-1250.

Steneck, R. S., Hughes, T. P., Cinner, J. E., Adger, W. N., Arnold, S. N., Berkes, F., ... \& Worm, B. (2011). Creation of a gilded trap by the high economic value of the Maine lobster fishery. Conservation Biology, 25(5), 904-912.

Stringer, L. C., Dougill, A. J., Fraser, E., Hubacek, K., Prell, C., \& Reed, M. S. (2006). Unpacking "participation" in the adaptive management of social-ecological systems: a critical review. Ecology and Society, 11(2), 39.

Suding, K. N., \& Hobbs, R. J. (2009). Threshold models in restoration and conservation: a developing framework. Trends in ecology \& evolution, 24(5), 271-279.

Suman, D., Shivlani, M., \& Walter Milon, J. (1999). Perceptions and attitudes regarding marine reserves: a comparison of stakeholder groups in the Florida Keys National Marine Sanctuary. Ocean \& Coastal Management, 42(12), 1019-1040.

Sutton, S. G. (2006). Understanding recreational fishers' participation in public consultation programs. Human Dimensions of wildlife, 11(5), 329-341.

Sutton, S. G., \& Tobin, R. C. (2012). Social resilience and commercial fishers' responses to management changes in the Great Barrier Reef Marine Park. Ecology and Society, 17, 1-10.

Turner, M., \& Weninger, Q. (2005). Meetings with costly participation: An empirical analysis. The Review of economic studies, 72(1), 247-268.

van de Koppel, J., Rietkerk, M., \& Weissing, F. J. (1997). Catastrophic vegetation shifts and soil degradation in terrestrial grazing systems. Trends in Ecology \& Evolution, 12(9), 352-356. 
Western, D., \& Pearl, M. C. (1989). Conservation for the Twenty-first Century. Oxford University Press. 


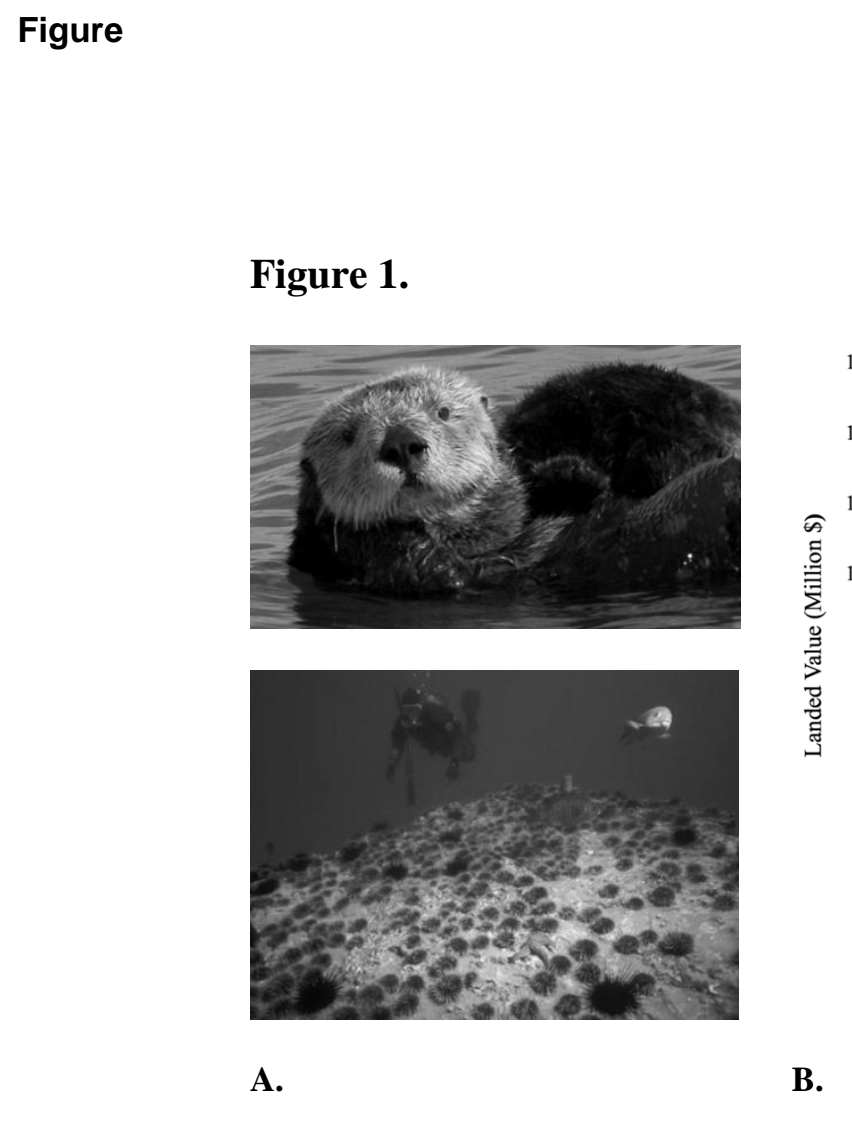
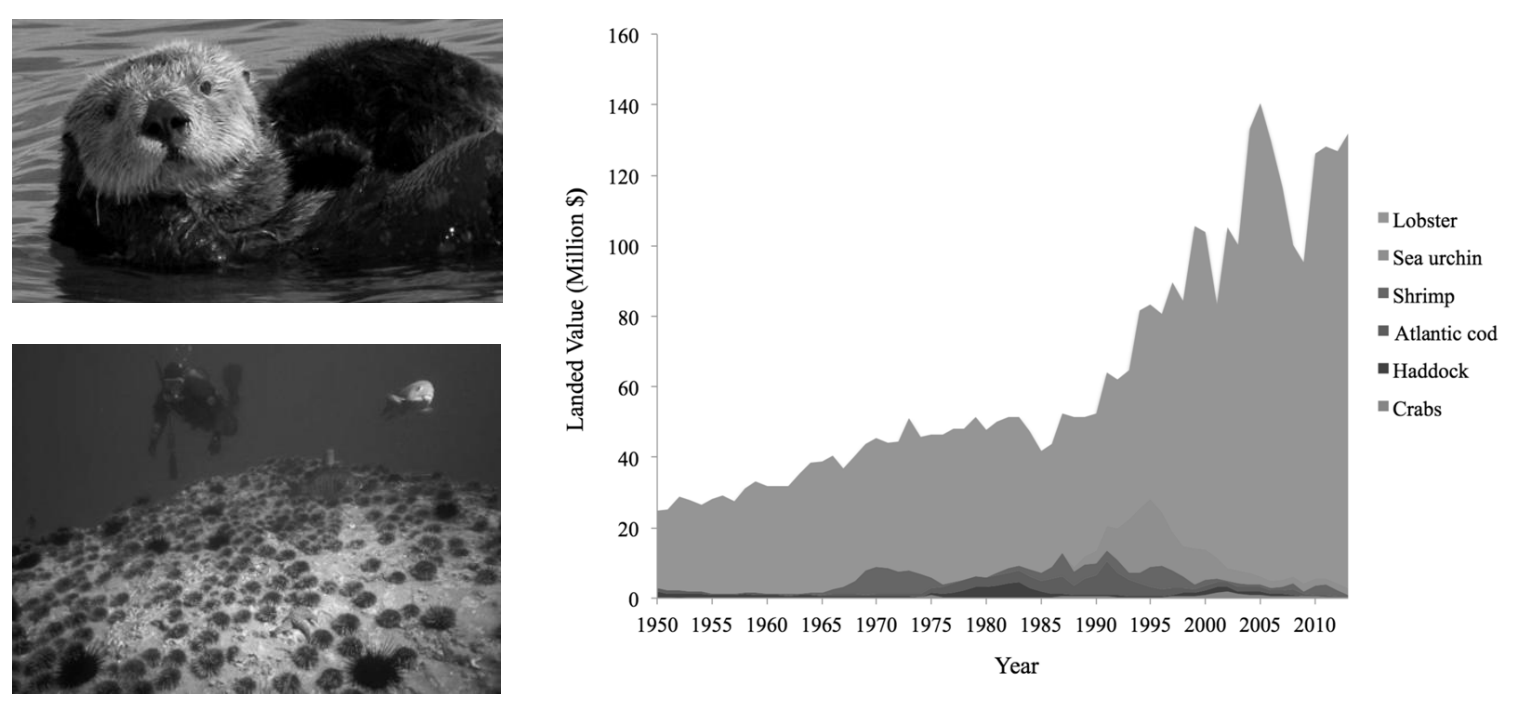

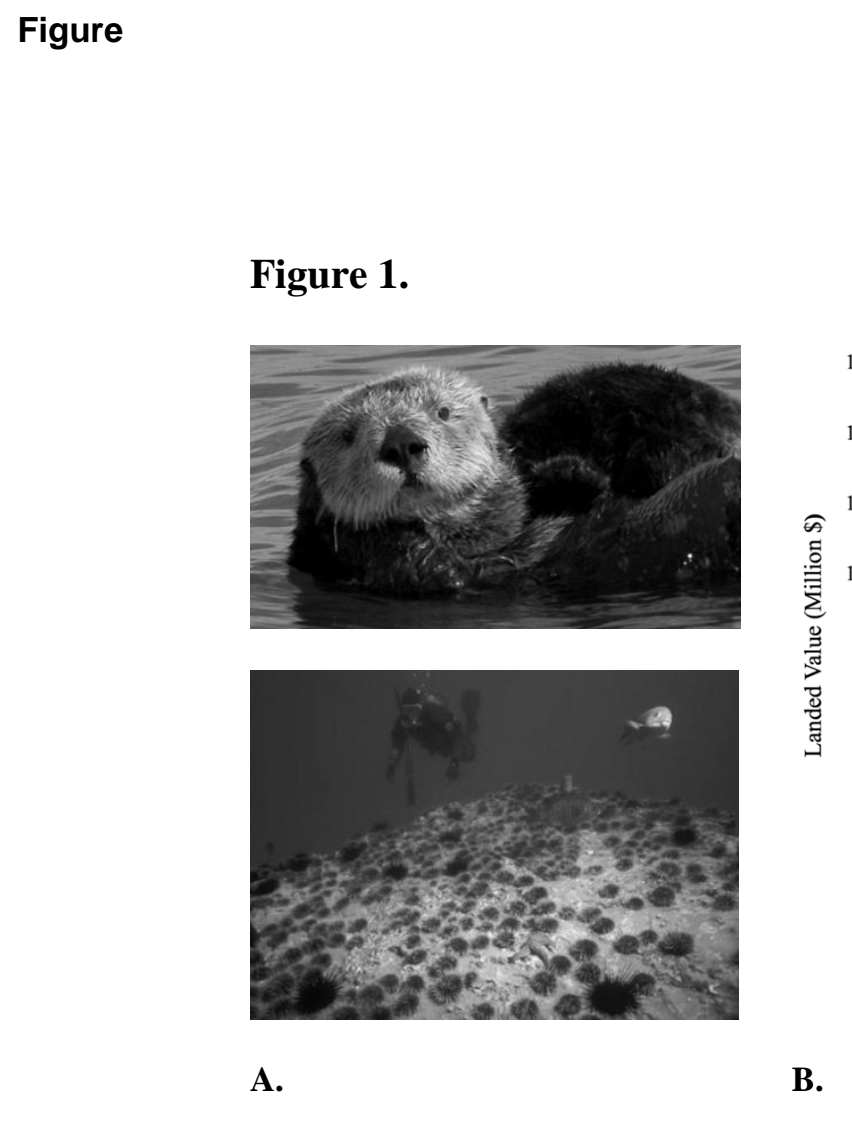

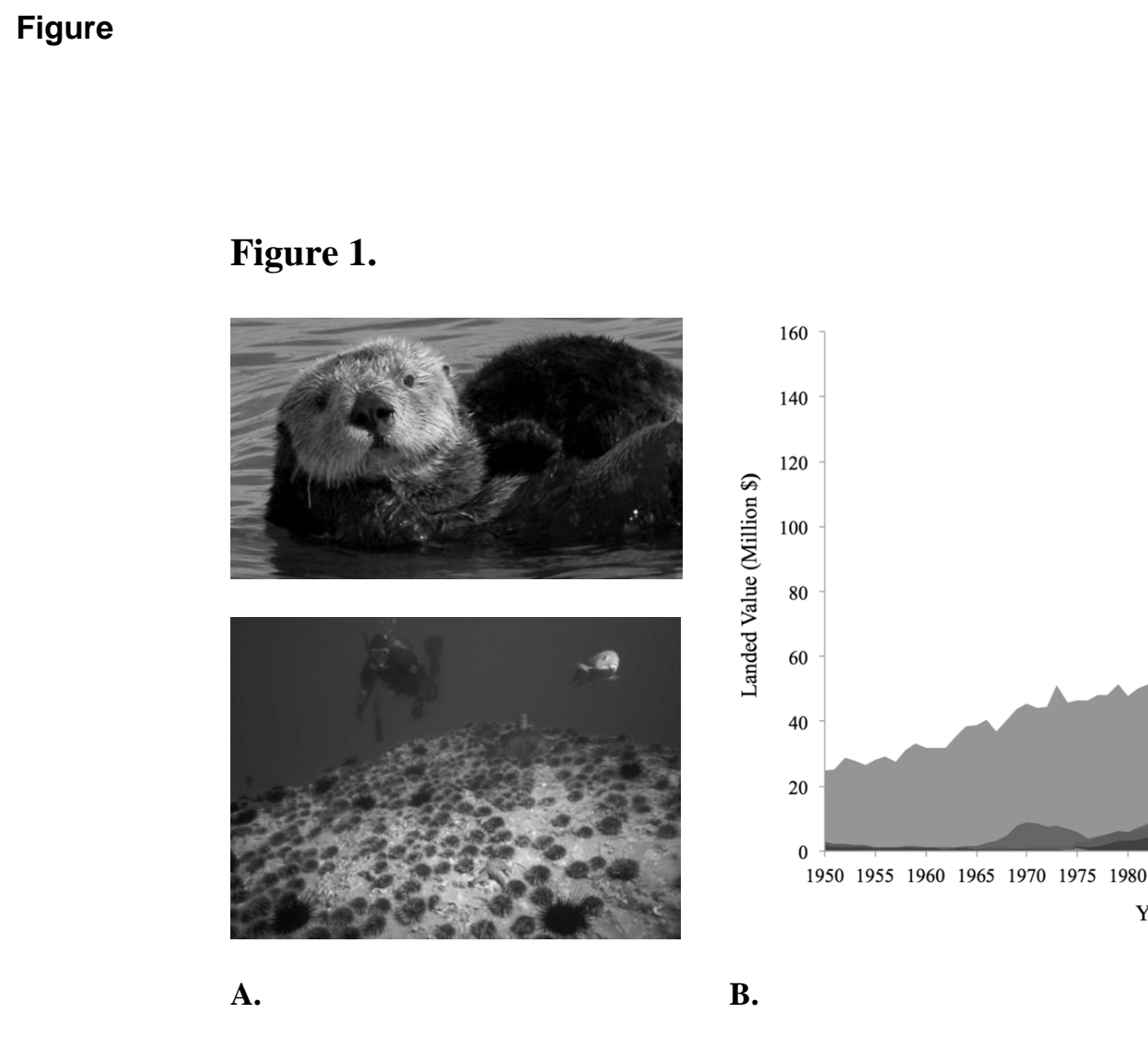

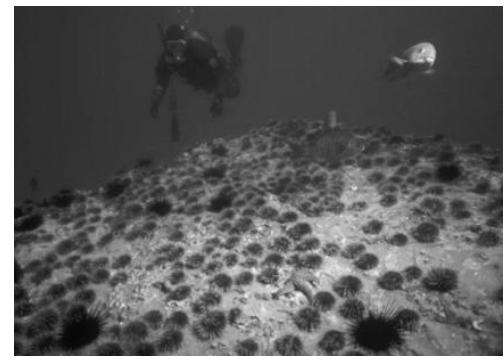

Sea urchin

Atlantic cod

Haddock

$\begin{array}{lllllllllllll}950 & 1955 & 1960 & 1965 & 1970 & 1975 & 1980 & 1985 & 1990 & 1995 & 2000 & 2005 & 2010\end{array}$ Year

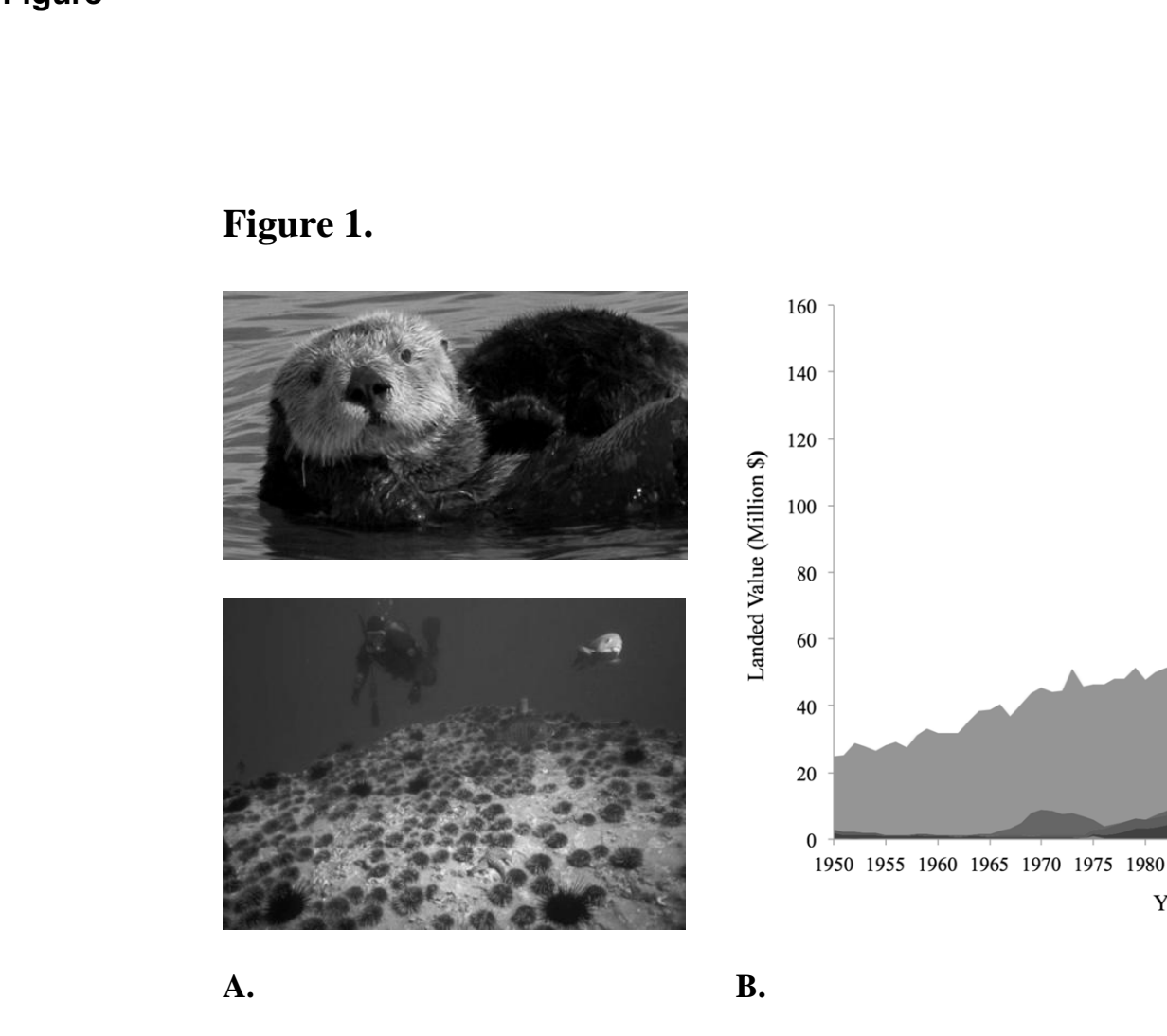

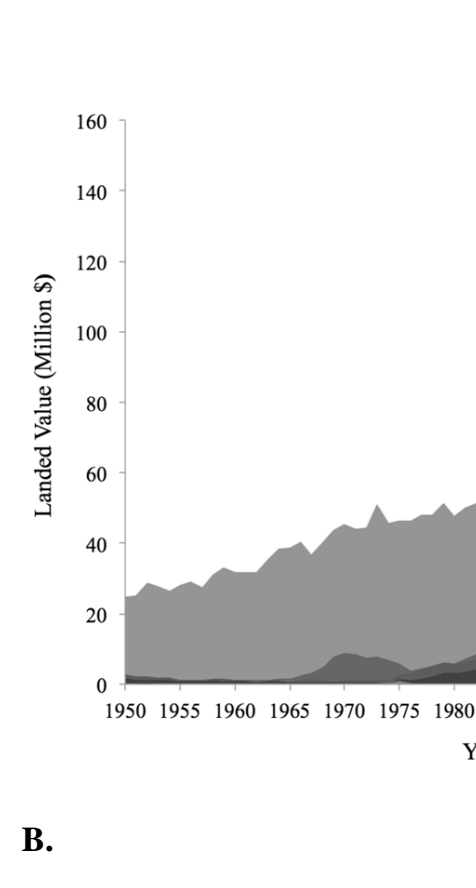

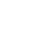

.

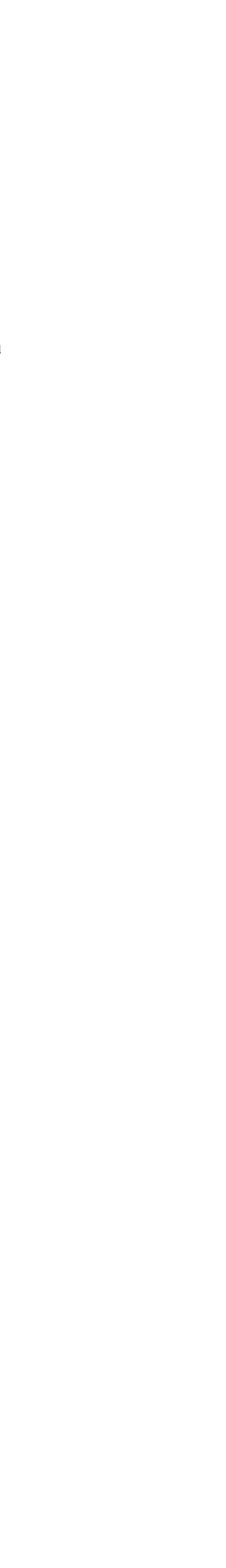

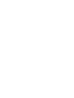




\section{Table 1.}

\begin{tabular}{|l|l|}
\hline Factor Affecting Participation & Explanation and Examples \\
\hline Travel cost & $\begin{array}{l}\text { The further away a meeting takes place from stakeholders, the more } \\
\text { likely only those with extreme positions will participate. Example: } \\
\text { Western Pacific Regional Fishery Management Council (Turner and } \\
\text { Weninger, 2005) }\end{array}$ \\
\hline Opportunity cost of time & $\begin{array}{l}\text { If a meeting takes place during working hours or for a long period } \\
\text { of time, this will discourage moderates. Example: Snapper Grouper } \\
\text { Visioning Project, Florida }\end{array}$ \\
\hline Degree of stake & $\begin{array}{l}\text { Those with the most to gain or lose are most likely to participate. } \\
\text { Example: Mid-Atlantic Fishery Management Council (Turner and } \\
\text { Weninger, 2005) }\end{array}$ \\
\hline Size of stakeholder group & $\begin{array}{l}\text { Individuals from larger groups are less likely to participate, so the } \\
\text { proportion involved in the process doesn't match the proportion in } \\
\text { the overall population. Example: California's MLPA process (Bard, } \\
\text { 2003) }\end{array}$ \\
\hline $\begin{array}{l}\text { Organizational capacity of } \\
\text { stakeholder group }\end{array}$ & $\begin{array}{l}\text { Groups currently benefitting from regime services are likely to have } \\
\text { more capital and infrastructure in place to engage than groups or } \\
\text { industries which have effectively dissolved following a regime shift } \\
\text { due to economic obsolescence in the new regime. Example: } \\
\text { Commercial abalone fishermen in California }\end{array}$ \\
\hline Trust in the process & $\begin{array}{l}\text { Those who do not trust that the management agency will listen to } \\
\text { their views will choose to not participate. Example: Florida Keys } \\
\text { National Marine Sanctuary (Suman et al., 1999) }\end{array}$ \\
\hline
\end{tabular}


Figure 1. Changes in dominant species and associated benefits under different ecosystem regimes. A. In Southern California, local extinction of sea otters in the early 1900s led to ecosystem shifts from kelp forests to urchin barrens on some rocky reefs, enabling lucrative sea urchin fisheries. Fisheries representatives, motivated to protect their livelihood, have vociferously lobbied for measures to counteract otter recovery. Top photo attribution: Michael L. Baird, http://bairdphotos.com/ (Creative Commons license). B. Fisheries value in the Gulf of Maine, corrected for inflation. Source data is the same as (10). Overfishing of cod in the first half of the $20^{\text {th }}$ century led to a regime shift whereby a cod regime was lost and replaced by lobster as the dominant predator, enabling a highly lucrative lobster fishery.

Figure 2. Simulated Variation in Opposition to Marine Reserves from High- and Low-Skill Fishers Low-skill and high-skill fishers are 10th and 90th percentile of the skill distribution, respectively. Upper Left scenario has pre-reserve stock size in the reserve fixed at half of its carrying capacity $(0.5 \mathrm{~K})$ and varies the prereserve stocks in the other sites. Upper Right fixes the pre-reserve stock in non-reserve sites at $0.5 \mathrm{~K}$ and varies the pre-reserve stock in the reserve. Lower considers the variation in WTP as the non-fishery earnings are increased, where the pre-reserve stock in other sites is set at 25\% (Lower Left) and 75\% (Lower Right) of its carrying capacity. In Lower, the pre-reserve stock in the reserve site is fixed at 0.5K. Source: Smith et al. (2010). 